\title{
Stability of maxillary advancement using external rigid distractors in cleft lip and palate patients
}

\author{
Sondos Abuzinada, Ahmed Alyamani \\ Department of Oral and Maxillofacial Surgery, King Abdulaziz University, Jeddah, KSA \\ Email: sondoz@hotmail.com
}

Received 20 September 2012; revised 25 October 2012; accepted 7 November 2012

\begin{abstract}
Purpose: To evaluate the skeletal changes associated with maxillary advancement using the external rigid distractor in cleft lip and palate patients after distraction and to assess the stability of these changes. Patients and Methods: Eight cleft lip and palate patients with maxillary hypoplasia underwent maxillary distraction osteogenesis using external rigid devise. Lateral cephalometric records were obtained before distraction $\mathrm{T} 1$ and after completing active distraction T2. After a three month follow up period a final lateral cephalometric record was evaluated T3. Results: The maxilla was significantly advanced as indicated by the increase in maxillary depth angle and effective maxillary length (median difference, $10 \mathrm{~mm}$ ). The palatal plane angle showed a significant increase (median difference, $5^{\circ}$ ), showing clockwise rotation. At T3 there was a slight decrease in maxillary depth angle (median difference, $3^{\circ}$ ). Effective maxillary length decreased significantly at T3 (median difference, 2 $\mathrm{mm}$ ). The palatal plane angle decreased (median difference, $3^{\circ}$ ) and almost returned to its original position, showing a counterclockwise rotation. Conclusion: Maxillary advancement using external rigid distractor resulted in clockwise rotation of maxilla with increase in palatal plane angle and slight increase in mandibular plane angle. The amount of maxillary advancement was slightly reduced during follow up and the palatal plane almost returned to its original position. These changes showed good stable clinical results.
\end{abstract}

Keywords: Maxillary Hypoplasia; Cleft Lip; Palate; Maxillary Distraction Osteogenesis

\section{INTRODUCTION}

The literature reports that $25 \%$ to $60 \%$ of cleft lip and palate (CLP) patients will need to undergo maxillary advancement for correction of midface hypoplasia $[1,2]$.
Ross et al. (1989) showed that about $25 \%$ of patients with unilateral cleft lip and palate develop maxillary hypoplasia that does not respond to orthodontic treatment alone [3]. Moreover, as a result of the severe maxillary hypoplasia, the mandible often undergoes anterior and superior autorotation with subsequent overclosure of the vertical dimension, resulting in a loss of facial height, pseudoprognathism, and upward inclination of the occlusal plane [4].

Maxillary advancement is the treatment of choice for maxillary hypoplasia in cleft lip and palate patients. This could be achieved using conventional Le fort I osteotomy and plate fixation $[5,6]$ or using distraction osteogenesis (DO). An adequate case selection for each method is extremely essential this should include the amount of desired advancement and the severity of palatal scaring present. It has been noted that the dense scar tissue present in most cleft palate patients play a role in post operative relapse [7].

Maxillary advancement using distraction osteogenesis using the Rigid Eternal Distractor (RED) provides an effective method for bone regeneration. Its use has become accepted world wide and it provides a better alternative treatment in patients with great tendency for relapse after maxillary advancement such as cleft lip and palate patients $[8,9]$. Many long term clinical follow up studies on maxillary distraction to advance the maxilla have demonstrated highly successful results [10-13]. However only a handful of studies reported the stability and relapse after maxillary distraction osteogenesis.

However relatively few studies on maxillary distraction have included data on stability and relapse. In addition most studies included growing and non growing patients from different age groups with residual mandibular growth that may have presented as relapse [10, 11]. One unique study only included adult cleft lip and palate patients who underwent maxillary distraction and were followed up for three year. They reported stable results with $22 \%$ relapse rate.

The purpose of this study is to evaluate the skeletal changes and stability of maxillary distraction osteogene- 
sis in cleft lip and palate patients. We report our experience and management.

\section{PATIENTS AND METHODS}

In this study we included eight cleft lip and palate patients who presented at the joint clinics of orthodontics and oral-maxillofacial surgery at king abdulaziz university hospital for evaluation time. All eight patients had severe maxillary hypoplasia. Five patients with bilateral cleft lip and palate and three patients with unilateral clefts. Their ages ranged between (15 - 20) mean age 16.2 years. Clinical examination revealed severe maxillary hypoplasia with a class III dental malocclusion and reverse overjet. All patients had normal mandibular growth and development according to cephalometric records.

They all underwent surgical repair of the cleft lip and palate at during the first two years of life. This was followed by surgical repair of the alveolar cleft using iliac bone graft at variable ages ranging between 11 - 15 years.

Initial records were obtained at T1 including clinical pictures, dental models and radiographs (orthopantograms OPG, lateral cephalometric). Cephalometric analysis was done using skeletal landmarks (Figure 1). All patients were started on orthodontic treatment for leveling, alignment and decompensation of the dental arches. After completing the presurgical orthodontic phase patients were referred back to the Oral and maxillofacial surgery department for surgical intervention. All eight patients had an occlusal discrepancy of $6 \mathrm{~mm}$ and more due to the hypoplastic maxilla.

Under general anesthesia and oral intubation a high Le Fort I osteotomy was performed and the maxilla was down fractured fixed to the RED using $2 \mathrm{~mm}$ plates and screws. After a 7 day latency period the distractor was activated at a rate of $1 \mathrm{~mm}$ per day in 2 rhythms. When the desired amount of maxillary advancement was achieved with an adequate occlusal overjet, the distraction was discontinued. After completing a three month consolidation period a second set of cephalometric records were obtained and the distractor was removed followed by a close postoperative follow up period. During the postoperative follow up all patients were assessed for any occlusal disturbances or interferences that may arise and a third set of cephalometric records were obtained after a three month follow up period (T3) (Figure 2).

\section{CEPHALOMETRIC EVALUATION}

Initial Lateral cephalograms were obtained before maxillary distraction (T1). A second record was taken immediately after completing the consolidation period (T2) and third evaluation was done at three months after removal of distractor (T3). The skeletal changes associated with maxillary distraction were traced and measured on

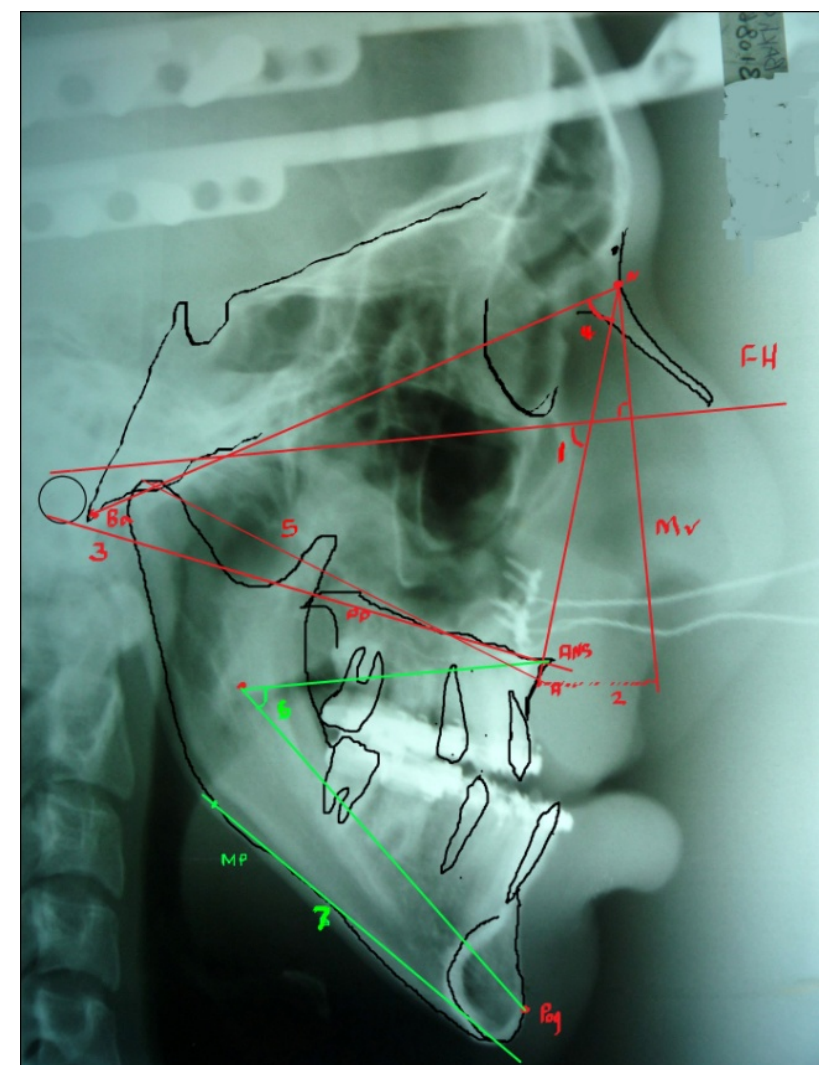

Figure 1. Skeletal measurements on cephalometric radiograph; 1. Maxillary depthangle $\left({ }^{\circ}\right)$ : angle between Frankfort horizontal plane and NA plane; 2. McNamara value $(\mathrm{mm})$ : shortest linear distance between point A and McNamara vertical (perpendicular line drawn from Na to Frankfort horizontal plane); 3. Palatal plane angle $\left({ }^{\circ}\right)$ : angle between Frankfort horizontal plane and palatal plane; 4 . Na-CF-A, angle between nasion-center of face (CF: point where the basion-nasion plane and Frankfort horizontal plane intersect) and center of face-point A; 5. Effective maxillary length $(\mathrm{mm})$ : distance between Co and A (Co: condylion, the most superior point on the head of the condylar head); 6. Lower facial height $\left({ }^{\circ}\right)$ : angle between lines ANS-X-Pog (X: the geometric center of the ramus of the mandible); 7. Mandibular plane angle: between Frankfort horizontal plane and mandibular plane.

the lateral cephalometric radiographs taken at T1, T2, T3. Ricketts [14] cephalometric analysis using skeletal points demonstrated in (Figure 1) was used to obtain all the measurements presented in (Table 1).

\section{Statistical Analysis}

A calculation of the mean, median values for each cephalometric variable listed in Table 1 was done. Changes in cephalometric variables after distraction at $\mathrm{T} 2$ was evaluated using the Friedman test with significance levels of $(\mathrm{P}<0.05)$. Comparisons were done to determine the significant differences amongT1, T2, T3 time interval to assess the accuracy of the method. Selected cephalograms were traced and recalculated by the same investigator. 

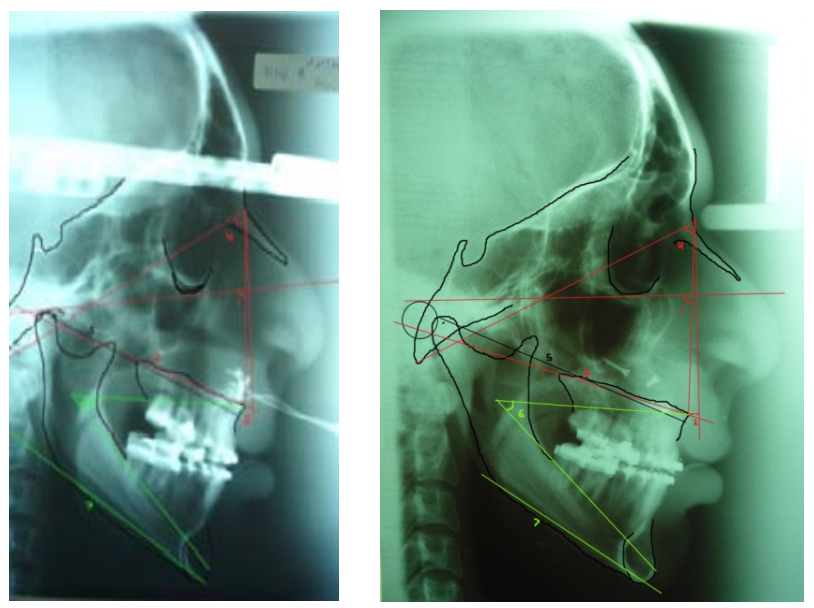

(a)

(b)

Figure 2. (a) Lateral Cephalomatric radiograph after completing the maxillary distraction with RED devise (T2); (b) Lateral Cephalometric radiograph at six months follow up post distractor removal (T3).

Table 1. Skeletal changes after maxillary distraction osteogenesis at $\mathrm{T} 1$ and $\mathrm{T} 2$ interval.

\begin{tabular}{|c|c|c|c|c|}
\hline Measurement & Median & Mean & Range & $P$ value \\
\hline \multicolumn{5}{|l|}{ Maxillary depth } \\
\hline $\mathrm{T} 1$ & 85 & 84 & $80-90$ & \\
\hline $\mathrm{T} 2$ & 91 & 95 & $85-110$ & $\mathrm{~T} 1-\mathrm{T} 2^{*}$ \\
\hline T3 & 90 & 93 & $85-107$ & $\mathrm{~T} 2-\mathrm{T}^{*}$ \\
\hline \multicolumn{5}{|l|}{ Effective maxillary length } \\
\hline $\mathrm{T} 1$ & 72 & 72.57 & $63-87$ & \\
\hline $\mathrm{T} 2$ & 82 & 83.71 & $76-96$ & $\mathrm{~T} 1-\mathrm{T} 2^{*}$ \\
\hline $\mathrm{T} 3$ & 80 & 81.85 & $75-95$ & $\mathrm{~T} 2-\mathrm{T} 3^{*}$ \\
\hline Mcnmara vertical & & & & NS \\
\hline $\mathrm{T} 1$ & -10 & -9 & -20 to -2 & \\
\hline $\mathrm{T} 2$ & 3.2 & 17 & -8 to 14 & \\
\hline $\mathrm{T} 3$ & -2 & 1 & -8 to 13 & \\
\hline Plalatal plane angle & & & & NS \\
\hline $\mathrm{T} 1$ & 7 & 8.21 & $5-15$ & \\
\hline $\mathrm{T} 2$ & 12 & 12.93 & $7-17$ & \\
\hline $\mathrm{T} 3$ & 9 & 11.86 & $5-15$ & \\
\hline Maxillary hight & & & & NS \\
\hline $\mathrm{T} 1$ & 52.50 & 55.28 & $46-76$ & \\
\hline $\mathrm{T} 2$ & 53.00 & 52.42 & $41-69$ & \\
\hline $\mathrm{T} 3$ & 53.00 & 52.57 & $41-68$ & \\
\hline Lower facial hight & & & & NS \\
\hline $\mathrm{T} 1$ & 49 & 50.21 & $43-82$ & \\
\hline $\mathrm{T} 2$ & 60 & 76.21 & $40-86$ & \\
\hline $\mathrm{T} 3$ & 55 & 58.27 & $39-87$ & \\
\hline Mandibular plane angle & & & & NS \\
\hline $\mathrm{T} 1$ & 28 & 33 & 30.1 & \\
\hline $\mathrm{T} 2$ & 35 & 39 & 34.2 & \\
\hline T3 & 33 & 35 & 31.4 & \\
\hline
\end{tabular}

${ }^{*} \mathrm{P}>0.05$.

\section{RESULTS}

Cephalometric changes after distraction from T1 to T2;

The maxilla was significantly advanced as indicated by the increase in maxillary depth angle (median difference, $6^{\circ}$ ) and effective maxillary length (median difference, $10 \mathrm{~mm})(\mathrm{P}<0.05)$.

The palatal plane angle showed a significant increase (median difference, $5^{\circ}$ ), showing clockwise rotation $(\mathrm{P}<$ $0.05)$. Skeletal maxillary sagittal movement was achieved in a superoanterior direction.

Cephalometric changes during postdisrtaction follow up from T2 to T3;

Slight decrease in maxillary depth angle (median difference, $\left.3^{\circ}\right)$. effective maxillary length decreased significantly at T3 (median difference, $2 \mathrm{~mm})(\mathrm{P}<0.05)$.

The palatal plane angle decreased (median difference, $\left.3^{\circ}\right)(\mathrm{P}<0.05)$ and almost returned to its original position, showing a counterclockwise rotation $(\mathrm{P}<0.05)$.

\section{DISCUSSION}

Reports have noted that most cleft lip and palate patients who underwent maxillary distraction were between 11 and 15 years of age [15]. Females show a decrease in maxillary growth after 12 years and in the mandible after 14 years of age. On the other hand, males seem to show growth in maxilla and mandible up to age 16 years [16]. In our study we selected patients with completed, maxillary growth and normally developed mandibles. All the patients except three females were older than 18years during the distraction phase of treatment.

The amount of advancement is a major factor to consider before performing conventional le fort I advancement. It has been noted that large maxillary advancements will lead to greater amount of relapse, however there are conflicting reports regarding the limit of maxillary advancement using conventional Le Fort I in cleft patients. Some reports note that in large advancements are those exceeding $10 \mathrm{~mm}$ [17]. Others define large maxillary advancements as those beyond $8 \mathrm{~mm}$ [18]. while others have reduced the limit of maxillary advancement to $5 \mathrm{~mm}$ with consideration of the palatal scar tissue formation [19]. All our patients had severe palatal scarring and required a maxillary advancement $>6 \mathrm{~mm}$.

Many factors contribute to a high rate of relapse after maxillary advancement including scarring from previous surgical repair of cleft lip and palate. Soft and hard tissue deficiencies are also contributing factors along with large maxillary advancements $[2,11]$. Cleft patients with severe maxillary hypoplasia treated with DO show highly promising results [11]. It has numerous advantages over conventional Le Fort I advancement. It allows large advancement of the underlying skeletal foundation with bony regeneration and elongation of the investing soft 
tissue. This gives better stability especially in cleft patients who require large advancements and present with severe palatal scaring [18]. Cheung compared relapse in clefts undergoing Le Fort I advancement of $5.3 \mathrm{~mm}$ with distraction group of $>6.7$. He reported better skeletal stability in the distraction group and greater relapse in the le fort I advancemnt due to soft tissue stretch [15].

In cleft lip and palate patients the maxillary hypoplasia is usually more severe and requires large advancements. In our study the effective maxillary length increased with a mean difference of $9 \mathrm{~mm}$. The most common range of maxillary advancement noted in the literature using distraction osteogenesis in cleft lip and palate patients was 5 to $9 \mathrm{~mm}$ [15]. The control of vertical movement during maxillary distraction maybe be a difficult task, however its importance and effect on occlusion and esthetics can not be ignored. We found a clockwise rotation of the maxilla during distraction with an increase in the mandibular plane angle. However, there was a slight counter clockwise rotation of the maxilla along with a return of mandibular plane angle to a position close to original. This change occurred after distractor removal and closure of the posterior open bite that as created during the distraction period using guiding elastics. Most reports showed clockwise rotation of the maxilla $[11,20]$ however, one study showed counter clockwise rotation of the maxilla after distraction [21].

It has been reported that the degree of maxillary advancement shows a decrease during the follow up period after distraction $[15,20]$. In our study the follow up period at T3 showed a slight decrease in the effective maxillary length with a mean difference of $2 \mathrm{~mm}$. The same was noted by a previous study showing stable results [14].

The stability of maxillary distraction osteogenesis is reinforced by the newly formed bony trabeculae in the pterygoid region. This bony formation is usually seen six weeks after the active distraction phase and plays a huge role in reducing the risk of relapse [22]. We applied a strict consolidation period of three months in order to ensure and preserve the bony formation in the pterygoid region. We have also added miniplate fixation with bone grafting in cases that showed thin anterior maxillary walls to add stability during distractor removal.

\section{CONCLUSION}

We have reported our experience in managing maxillary hypoplasia in cleft lip and palate patients. We have also demonstrated the effect of maxillary distraction and the associated skeletal changes that occur after distraction and during the follow up period. Maxillary advancement using external rigid distraction gives satisfactory stable results when used on cleft lip and palate patients that require large advancements beyond $6 \mathrm{~mm}$. Stability of this procedure could be maintained by a strict consolidation period of three months.

\section{ACKNOWLEDGEMENTS}

We thank Dr. A. Boker, Consultant anesthesiologist at King Abdulaziz University for his assistance with the statistics in this study.

\section{REFERENCES}

[1] Panula, K., Lorius, B. and Popisil, O. (1993) The need for orthognathic surgery in patients born with complete cleft palate or complete unilateral cleft lip and palate. Oral Surgery, Oral Diagnosis, 4, 23.

[2] Rachmiel, A. (2007) Treatment of maxillary cleft palate: Distraction osteogenesis versus orthognathic surgeryPart one: Maxillary distraction. Journal of Oral and Maxillofacial Surgery, 65, 753-757. doi:10.1016/j.joms.2006.08.010

[3] Ross, R. (1987) Treatment variables affecting facial growth in complete unilateral cleft lip and palate: An overview of treatment and facial growth. Cleft PalateCraniofacial Journal, 24, 71-77.

[4] Scolozzi, P. (2008) Distraction Osteogenesis in the management of severe maxillary hypoplasia in cleft lip and palate patients. Journal of Craniofacial Surgery, 19, 1199-1214. doi:10.1097/SCS.0b013e318184365d

[5] Stoelinga, P.J.W., vd Vijver, R.M., Leenen, R.J., et al. (1987) The prevention of relapse after maxillary osteotomies in cleft palate patients. Journal of Cranio-Maxillofacial Surgery, 15, 326-331. doi:10.1016/S1010-5182(87)80078-1

[6] Adlam, D. and Banks, P. (1989) A retrospective study of the stability of midface osteotomies in cleft lip and palate patients. British Journal of Oral and Maxillofacial Surgery, 27, 265-276. doi:10.1016/0266-4356(89)90037-5

[7] Hirano, A. and Suzuki, H. (2001) Factors related to relapse after Le Fort Imaxillary advancement osteotomy in pateints with cleft lip and palate. Cleft Palate-Craniofacial Journal, 38, 1-10.

doi:10.1597/1545-1569(2001)038<0001:FRTRAL $>2.0 . C$ $\underline{\mathrm{O} ; 2}$

[8] Figueroa, A., Polley, J. and Ko, E. (1999) Maxillary distraction for the management of cleft maxillary hypoplasia with rigid external distraction system. Seminars in $\mathrm{Or}$ thodontics, 5, 46-51. doi:10.1016/S1073-8746(99)80042-5

[9] Rachmiel, A., Aizenbud, D., Ardekian, L., et al. (1999) Surgically-assisted orthopedic protraction of the maxilla in cleft lip and palat patients. International Journal of Oral and Maxillofacial Surgery, 28, 9-14. doi:10.1016/S0901-5027(99)80668-7

[10] Wiltfang, J., Hirschfelder, U., Neukam, F. and Kessler, P. (2002) Long-term results of distraction osteogenesis of the maxilla and midface. British Journal of Oral and Maxillofacial Surgery, 40, 473-479. doi:10.1016/S0266435602002474 
[11] Figueroa, A., Polley, J., Friede, H. and Ko, E.W. (2004) Long-term skeletal stability after maxillary advancement with distraction osteogenesis using a rigid external distraction device in cleft maxillary deformities. Plastic and Reconstructive Surgery, 114, 1382-1393.

[12] Rachmiel, A., Aizenbud, D. and Peled, M. (2005) Long term results in maxillary deficiency using intraoral devices. International Journal of Oral and Maxillofacial Surgery, 34, 473-479. doi:10.1016/j.ijom.2005.01.004

[13] Harada, K., Sato, M. and Omura, K. (2005) Long-term skeletal and dental changes in patients with cleft lip and palate after maxillary distraction: A report of three cases treated with a rigid external distraction device. Cranio, 23, 152-157.

[14] Ricketts, R.M., Bench, R.W., Gugino, C.F., et al. (1980) Bioprogressive therapy. Rocky Mountain Orthodontics, Denver.

[15] Cheung, L. and Chua, H. (2006) A meta-analysis of cleft maxillary osteotomy and distraction osteogenesis. International Journal of Oral and Maxillofacial Surgery, 35, 14-24. doi:10.1016/j.ijom.2005.06.008

[16] Ochoa, B. and Nanda, R. (2004) Comparison of maxillary and mandibular growth. American Journal of Orthodontics \& Dentofacial Orthopedics, 125, 148-159. doi:10.1016/j.ajodo.2003.03.008

[17] Precious, D. (2007) Treatment of retruded maxilla in cleft lip and palate-Orthognathic surgery versus distraction osteogenesis: The case for orthognathic surgery. Journal of Oral and Maxillofacial Surgery, 65, 758-761. doi:10.1016/j.joms.2006.08.011

[18] Kanno, T., Mitsugi, M., Hosoe, M., Sukegawa, S., et al. (2008) Long-term skeletal stability after maxillary advancement with distraction osteogenesis in non-growing patients. Journal of Oral and Maxillofacial Surgery, 66, 1833-1846. doi:10.1016/j.joms.2007.10.013

[19] Wang, X., Yi, B., et al. (2005) Internal midface distraction in correction of severe maxillary hypoplasia secondary to cleft lip and palate. Plastic and Reconstructive Surgery, 116, 51-60. doi:10.1097/01.PRS.0000169691.22783.29

[20] Harada, K., Baba, Y., Ohyama, K., et al. (2001) Maxillary distraction osteogenesis for cleft lip and palate children using an external, adjustable, rigid distraction device: A report of 2 cases. Journal of Oral and Maxillofacial Surgery, 59, 1492-1496. doi:10.1053/joms.2001.28292

[21] Aksu, M., Saglam, B., Akcan, C., et al. (2010) Skeletal and dental stability after maxillary distraction with a rigid external device in adult cleft lip and palate patients. Journal of Oral and Maxillofacial Surgery, 68, 254-259. doi:10.1016/j.joms.2009.03.030

[22] Kusnoto, B., Figueroa, A. and Polley, J. (2001) Radiographic evaluation of bone formation in the pterygoid region after maxillary distraction with a rigid external distraction (RED) device. Journal of Craniofacial Surgery, 12, 109-117. doi:10.1097/00001665-200103000-00003 